\title{
Knowledge, Attitude, and Practice Toward Pet Contact Associated Zoonosis in Western Ethiopia
}

\author{
Yobsan Tamiru (D), Debela Abdeta (D), Morka Amante (D) \\ School of Veterinary Medicine, Wollega University, Nekemte, Ethiopia \\ Correspondence: Debela Abdeta, Email debela.abdeta@gmail.com
}

Background: Households consider their dogs and cats as their close friends. They act as companion animals. The contact between pets and their owners results in transmission of zoonotic disease. In Ethiopia, dogs and cats are the most abundant carnivores, and diseases associated with them affect wide parts of the community. There is limited knowledge, practice, and attitude within the communities toward pet contact associated zoonotic disease.

Methods: A community-based semi-structured questionnaire complemented with an interview was delivered to 633 household pets' owners in Sibu Sire, Jimaa Arjo, and Wayu Tuqa districts in Western Ethiopia to evaluate knowledge, attitude, and practices toward pet contact associated zoonotic disease.

Results: Socio-demographically, $54.6 \%$ of the study participants were female. According to this finding concerning common pet contact zoonotic disease, $70 \%$ of the respondents had knowledge about rabies, with Echinococcosis, toxoplasmosis, and ring worm also being commonly heard of. Contamination of feed and water $(21.71 \%)$ and animal bites $(21.01 \%)$ are the predominant modes of transmission, whereas animal waste, fecal oral route, and touching pets are also common ways for disseminating zoonotic disease. The dominant symptoms noted by respondents were behavioral change, depression, lack of appetite, itching, and diarrhea. In all attitude-related responses, there was a significant association $(\mathrm{p}<0.05)$ between the number of respondents and the variable studied. There was also a statistically significant association of KAP score $(\mathrm{p}<0.05)$ with educational rank and the work of respondents.

Conclusion: This study indicates the importance of pet ownership to the community, which is also associated with transmitting different zoonotic diseases. Moreover, there are inconsistencies on regular veterinary use, pet management, and proper prevention and treatment measures of the disease. Coordinated efforts are expected from different stakeholders in enhancing community KAP level towards pet contact associated zoonosis.

Keywords: attitude, community, knowledge, pet, practice, zoonosis, Western Ethiopia

\section{Introduction}

Household pets can be defined as any animal kept by human beings as a source of companionship and pleasure. From prehistoric times until the present, pet keeping has served as a cultural and social need in nearly every society and culture. It is likely that the dog and cat are the most domesticated pet species in many countries, including Ethiopia. ${ }^{1,2}$ Ethiopia has as estimated more than 5 million dogs and 150,000 cats. Pets are among the main reservoirs and transmitters of many zoonotic infections caused by viruses, bacteria, protozoa, fungus, and helminthic diseases, such as Rabies, Leptospira, toxoplasmosis, Ringworm, and Echinococcosis, respectively. Zoonotic diseases are said to account for $60 \%$ of all infectious diseases and $75 \%$ of all emerging pathogens. ${ }^{3}$ Pet contact borne zoonoses, like Toxoplasmosis, Rabies, and Echinococcosis, were reported in Ethiopia. ${ }^{3-5}$

Direct contact between household pets and people by petting, licking, and physical injuries, or indirectly through contamination of food and domestic environments, offer favorable conditions for disease transmission. Indeed, bites are one of the most common sources of bacterial skin infection. Frequent sharing of skin microbiota between people and their dogs has been shown, thus emphasizing the role of contact. ${ }^{1,6,7}$ Skin wounding via animal bite results in infections 


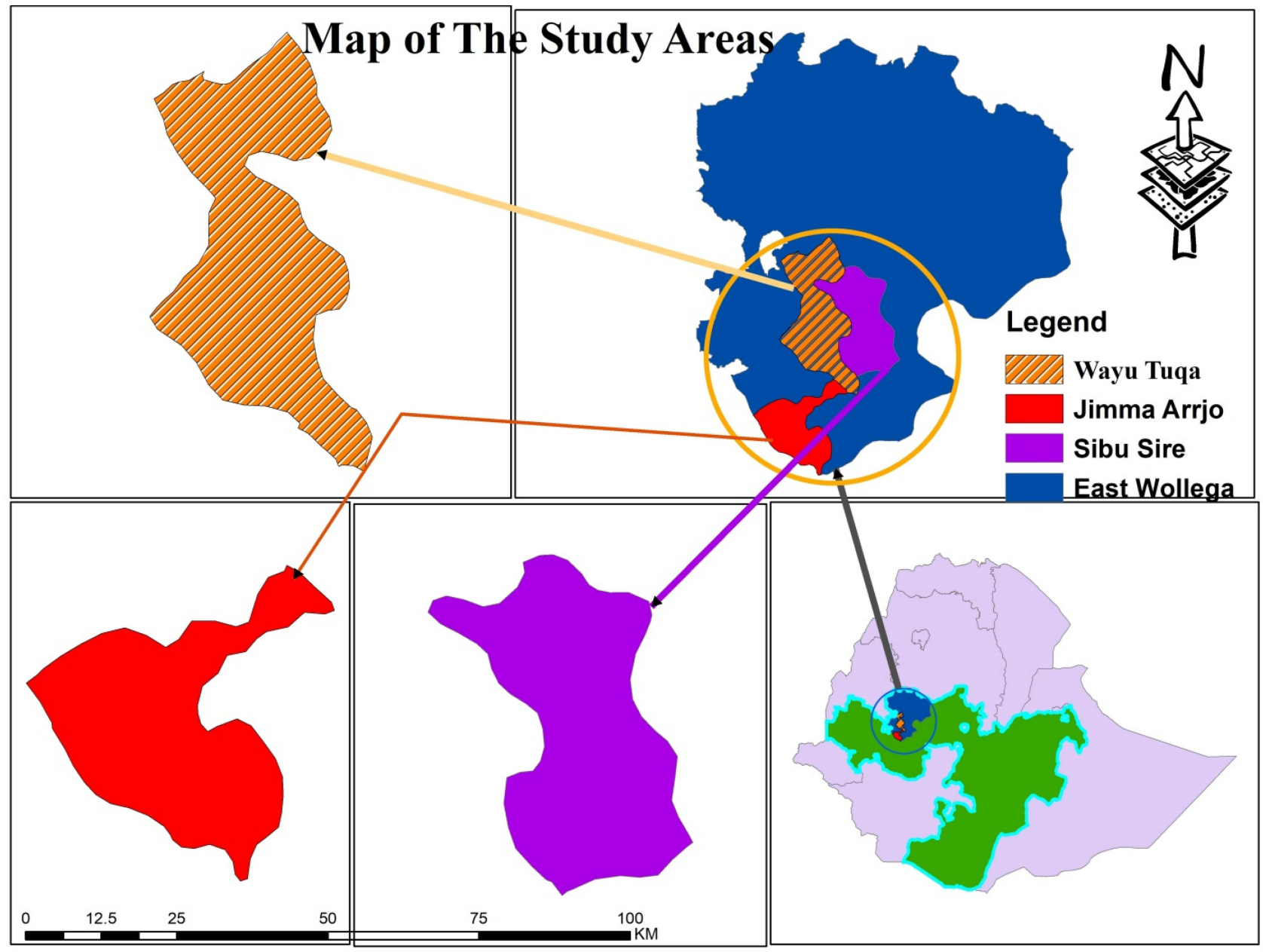

Figure I Map showing the study area.

caused by a wide range of bacteria existing in the oral mucosa of pets and skin of the bitten individual. Pasteurella multocida and $P$. canis are the most common bacteria transmitted by cat and dog bites. ${ }^{7,8}$

Toxoplasma gondii is transmitted to humans through accidental ingestion of sporulated oocyst or consumption of raw or under cooked meat. Cats play an important role in the spread of this disease. The parasite is passed in the cat's feces in an oocyst form, which is microscopic. Kittens and cats can shed millions of oocysts in their feces for as long as 3 weeks after infection. Echinococcosis pass through consumption of under cooked beef or pork meat and dogs play a role in its transmission via completion of its life cycle. ${ }^{9}$ Bartonellosis, also called cat-scratch disease, is by far the common zoonotic disease associated with cats. ${ }^{10}$ Individuals with compromised immune systems may suffer more severe, even fatal consequences. ${ }^{11}$ Rabies is most commonly transmitted by dogs via biting. ${ }^{1}$

Zoonotic diseases are of exceptional alarm for young and old people, pregnant mothers, and immunocompromised groups. Moreover, young children are probably exposed to microorganisms originating from pets due to limited sanitation standards and closer physical contact within the animals' environment, like the floor and carpets. ${ }^{12}$ Children frequently put their hands in their mouths, allowing an easy route for bacteria to travel into their system. These groups of individuals most commonly like to play with puppies and kittens which are more likely to carry a disease than older dogs and cats. ${ }^{13}$ The soil is an important route of transmission for numerous human pathogens such as Ascaris lumbricoides, Trichuris trichiura, Ancylostoma duodenale, Necator americanus, and Strongyloides stercoralis, which are commonly shed by pets. ${ }^{14,15}$

Nowadays zoonotic diseases, particularly pet borne diseases, affect a population of 1 million and pose huge losses. Zoonotic diseases that occur in Ethiopia in large numbers impact the society in three main ways: they threaten the health 
of the animals, resulting in illness, loss of productivity, and death; they threaten the livelihood of a large segment of the population dependent on livestock as a major source of food and income; and finally they cause a large number of illnesses and deaths in people, which is associated with significant economic and societal loss. ${ }^{16}$

Despite the fact that many pets are owned by households, the community has varying opinions on how they should be managed. These days, the community is at risk of many zoonosis outbreaks caused by pet contact. The development and implementation of effective disease prevention and control strategies require a thorough understanding of communities' attitudes and practices regarding contact-borne zoonotic diseases. Thus, awareness of good pet husbandry, sanitation practices, and the risk of zoonotic disease in pets is required for effective disease prevention. ${ }^{4,17}$ Therefore, the objective of this study was to characterize the public's knowledge, attitudes, and practice towards pet contact associated zoonosis in western Ethiopia.

\section{Materials and Methods}

\section{Study Area}

A cross-sectional community based study was conducted from October 2019-June 2020 in selected districts of East Wollega Zone (Figure 1). The zone has 17 districts and covers $14,102.5 \mathrm{~km}^{2}$, which accounts for about $3.88 \%$ of the total area of the Oromia regional state and has a population of 1,199,444. The vegetation type of the area is characterized by riverine vegetation and savanna grass lands. Wild animals found in the vegetation area include baboons, monkeys, African buffalo, bush pigs, warthogs, crocodiles, hyenas, snakes, elephants, giraffes, and apes. Nekemte is the capital of Guto Gida and the zone is found at $328 \mathrm{~km}$ west of Addis Ababa, in Oromia regional national state, Ethiopia.

Arjo town is found in Oromia regional state, eastern Wollega zone, $377 \mathrm{~km}$ from Addis Ababa and $48 \mathrm{~km}$ from Nekemte zonal city. It is located at an altitude of 1,500-2,400 m above sea level. It has a rainfall of 1,800-2,700 mm with a temperature of $15-24^{\circ} \mathrm{C}$. Wayu Tuqa district is $316 \mathrm{~km}$ west of Addis Ababa. Topographically the district constitutes highlands, midlands, and lowlands with an elevation ranging from 1,729 to 2,740 m above sea level. Sibu Sire district is located $270 \mathrm{~km}$ west of Addis Ababa, the capital of the country. It lies at $8^{\circ} 56-9^{\circ} 23^{\prime} \mathrm{N}$ latitude and $36,035^{\prime}-3,656^{\prime}$ E longitudes. The altitude of the district varies from 1,336 to $2,500 \mathrm{~m}$ above sea level. It has an estimated area of $1,132.51 \mathrm{~km}^{2}$. About $74.2 \%, 7.53 \%$, and $18.27 \%$ of its surface area belongs to mid-altitude, highland, and lowland agro climates, respectively. The mean annual temperature and rainfall is $25^{\circ} \mathrm{C}$ and $1,050 \mathrm{~mm}$, respectively. ${ }^{18}$

\section{Study Design}

The study was conducted to assess knowledge, attitude, and practice related to pet contact and associated zoonotic diseases. Assessment approaches include a well-designed interview and questionnaire. A random sampling method was used to select 633 respondents for a questionnaire interview. The semi-structured and open-ended questionnaires were used on either male or female households who were above 15 years old, and own either a dog or cat or both. The questionnaire was designed to evaluate the knowledge of respondents concerning the mode of zoonotic diseases transmission, symptoms of diseases, control, and prevention measures, whereas household concern about children-pet contact, the importance of pets for the family, and the benefits of owning a pet over its risk were attitude questions; regular veterinary service for pets, feeding, sleeping area, offal management, and feces disposal were practice question raised for respondents.

To measure the level of various aspects of KAP, the questionnaire was divided into three distinct categories. The analysis of the category module was done based on a scalar scoring method. There are two types of questions, with some questions having two possible answers, which were given one point for a correct response and zero points for an uncertain response. The other type of question had three levels, of score 0,1 , and 2, representing poor, fair, and good levels of KAP. Total KAP score is used to rank the level of KAP and qualitative analysis was conducted to rank high, medium, and low scores. Overall there were 25 questions in the questionnaire. Those respondents who obtained a KAP 
score above 50\% were considered as high level, $25-50$ was a medium score, while the low score level was if less than $25 .{ }^{19}$

\section{Sample Size Determination}

The sample size was calculated using a single population proportion formula. The respondents were randomly selected from purposively covered districts. The questions were answered by a single adult from a given household. Accordingly, assuming a proportion of knowledge level of $83 \%$, attitude level $52.3 \%$, and practice level $68 \%,{ }^{20}$ with a margin error of $5 \%$, confidence level of $95 \%$, and 1.5 design effect, the calculated sample sizes for knowledge, attitude, and practice were 217,383 , and 340 , respectively. Therefore, the larger sample size among the KAP is taken as appropriate, which is 383 multiplied by a 1.5 design effect and a $10 \%$ non-response rate was added. Finally the sample size was determined to be $(383 * 1.5)+(0.1 * 575)=633$ individuals.

\section{Data Management and Analysis}

Data generated was entered into an MS-Excel sheet and analyzed using IBM-SPSS version 20. Descriptive statistics were used to measure the frequency of distribution of sociodemographic factors, and KAP of the respondents towards pet contact associated zoonotic disease. Moreover, a statistical association between the practice of respondents toward management of pet contact associated zoonosis and educational status of the respondents was analyzed by chi-square test. The KAP score was measured and its association was assessed in relation to household demography using a chi-square test. $P$-values less than 0.05 were considered as statistically significant at a $95 \%$ confidence level. Finally the analyzed data were presented in tabular and narrative forms, as per necessity.

\section{Data Quality Control}

The questionnaire was piloted on 10 members of the community with a history of pet contact and we studied a previous report on disease. Close supervision was undertaken during the data collection by the research group. The questionnaire was checked for completeness and consistency before data entry by the investigators.

\section{Ethical Clearance}

Ethical approval for this research was obtained from Wollega University, School of Veterinary Medicine, Nekemte Campus, with minute number WU-SVM-IRB0012, dated September 2019. Before starting the interview, oral consent was also obtained from the pet owners after verbal informed consent was approved by the Wollega University ethics committee. The participants were informed about the purpose of the study and parental/legal guardian informed consent was obtained for participants under the age of 18.

\section{Results}

\section{Demographic Characteristics of Respondents}

Out of 633 respondents, $322(50.80 \%)$ of them were greater than 25 years and $311(49.20 \%)$ of them were below 25 years of age. There were $346(54.6 \%)$ female respondents to the questionnaire, representing the majority. From educational background outlooks, 203 (32.1\%) of the households belong to Grade 5-8 followed by Grade 10, covering 30.8\% (195) of the participants. The proportion of individuals learning to Grade 1-4 and non-formal educated were $11.7 \%$ (74), and 13.8\% (87), respectively. Out of 633 respondents, $80 \%$ (190) were married. Furthermore, 57.1\% (361) of them were farmers (Table 1).

\section{Pet Ownership and Purpose for Keeping}

Among the total participants, $425(67.08 \%)$ and 45 (7.1\%) had only dogs or cats, respectively, and $164(25.8 \%)$ respondents had both dogs and cats in their household. From the total pet owners, 245 (38.8\%) of them kept their pet for guarding purposes, whereas $87(13.8 \%)$ and $119(18.7 \%)$ of the respondents kept their pet for guarding and pleasure or relaxation, as well as for guarding and hunting, respectively. Also, $166(26.3 \%)$ of them kept them for hunting purposes as is summarized in Table 2 . 
Table I Socioemographics of the Respondents

\begin{tabular}{|c|c|c|c|}
\hline Factors & Level & Frequency (\%) & $P$-value \\
\hline \multirow[t]{3}{*}{ Districts } & Sibu sire & 33.33 & 0.93 \\
\hline & Jimma Arjo & 33.33 & \\
\hline & Wayu Tuqa & 33.33 & \\
\hline \multirow[t]{2}{*}{ Age } & $\leq 25$ & 49.20 & 0.847 \\
\hline & $>25$ & 50.83 & \\
\hline \multirow[t]{2}{*}{ Sex } & Female & 54.60 & 0.175 \\
\hline & Male & 45.40 & \\
\hline \multirow[t]{5}{*}{ Education } & College/University & 11.70 & 0.004 \\
\hline & Grade I-4 & 11.70 & \\
\hline & Grade 10 & 30.80 & \\
\hline & Grade 5-8 & 32.10 & \\
\hline & No formal education & 13.80 & \\
\hline \multirow[t]{2}{*}{ Marital status } & Married & 80.00 & 0.001 \\
\hline & Unmarried & 20.00 & \\
\hline \multirow[t]{3}{*}{ Occupation } & Farmer & 57.1 & 0.033 \\
\hline & Merchant & 34.2 & \\
\hline & Professional & 8.75 & \\
\hline
\end{tabular}

Table 2 Pet Ownership and Purpose for Keeping

\begin{tabular}{|l|l|l|l|l|}
\hline Variables & Category & Number & Frequency (\%) & $P$-value \\
\hline Which type of pet do you keep? & Dog & 424 & 67.1 & 7.1 \\
& Cat & 45 & 25.8 & 0.001 \\
For what purpose do you keep the pet? & Both Cat and Dog & 164 & 38.8 & 13.8 \\
& Guard & 245 & 18.7 & 2.1 \\
& Guard and pleasure & 87 & 119 & 26.3 \\
& Guard and hunting & 13 & 0.83 \\
\hline
\end{tabular}

\section{Knowledge of the Respondents Toward Pet Contact Associated Zoonosis}

Out of total participants, $70 \%$ of them had heard of rabies as one of the common pet contact associated diseases, whereas 9.32\% and $7.08 \%$ of them knew about Echinococcosis and ring worm, respectively. Overall, $7.27 \%$ of respondents had heard about all the zoonotic diseases surveyed (Table 3). Regarding modes of transmission, $63.3 \%$ of the respondents replied that pet contact associated zoonoses were transmitted through biting, $13.75 \%$ of respondents noted the fecal-oral route, $5.41 \%$ responded that those diseases were transmitted through biting and touch, and $17.5 \%$ acknowledged biting and scratches (Table 3).

The source of information was also assessed and $78.8 \%, 4.2 \%$, and $17.1 \%$ of the respondents heard the information from a neighbor, the media, and health professionals, respectively (Table 3). The results also indicated that the most common symptom mentioned was $20 \%, 17.85 \%$, and $15.48 \%$ for behavioral change, loss of appetite, and diarrhea, respectively. Moreover, 23.33, 0.42 , and $2.5 \%$ of the respondent replied that pet contact diseases were protected by confining and vaccination, confining only, and washing and vaccination only, respectively. From the total respondents, $24.52 \%$ use tradition treatments like the use of herbal or medicinal animals to cure diseases like ring worm, rabies, and parasitic zoonosis (Table 3). 
Table 3 Knowledge of Respondents Toward Pet Contact Associated Zoonosis

\begin{tabular}{|c|c|c|c|}
\hline Variables & Category & Number & $\begin{array}{l}\text { Percentage } \\
\text { (\%) }\end{array}$ \\
\hline \multirow[t]{5}{*}{ Which pet contact diseases do you know? } & Echinococcosis & 59 & 9.32 \\
\hline & Toxoplasmosis & 40 & 6.32 \\
\hline & Rabies & 443 & 70.00 \\
\hline & Ring worm & 45 & 7.08 \\
\hline & All & 46 & 7.27 \\
\hline \multirow[t]{6}{*}{ What are the modes disease transmission? } & Bite & 133 & 21.01 \\
\hline & Bite and scratch & 111 & 17.5 \\
\hline & Bite and touch & 34 & 5.41 \\
\hline & Fecal-oral route & 87 & 13.75 \\
\hline & Animal waste & 130 & 20.54 \\
\hline & Feed and water contamination & 134 & 21.71 \\
\hline \multirow[t]{2}{*}{ Have you got any access to pet management training? } & Yes & 84 & 86.7 \\
\hline & No & 549 & 13.3 \\
\hline \multirow[t]{5}{*}{ Where did you hear about pet contact diseases? } & Neighbor & 498 & 78.8 \\
\hline & Media & 26 & 4.2 \\
\hline & Professional & 108 & 17.1 \\
\hline & Behavioral change & 127 & 20.0 \\
\hline & Loss of body weight & 79 & 12.48 \\
\hline What are the symptoms of the pet contact disease you & Loss of appetite & 113 & 17.85 \\
\hline \multirow[t]{4}{*}{ acknowledged? } & Itching & 55 & 8.69 \\
\hline & Nervous & 95 & 15.00 \\
\hline & Swelling & 66 & 10.42 \\
\hline & Diarhoea & 98 & 15.48 \\
\hline \multirow[t]{5}{*}{ How do you protect pets from disease? } & Vaccination & 169 & 26.70 \\
\hline & Sanitation & 102 & 16.11 \\
\hline & Isolation & 134 & 21.17 \\
\hline & All & 200 & 31.59 \\
\hline & Do nothing & 28 & 4.42 \\
\hline \multirow[t]{5}{*}{ How do you treat diseased pets? } & Traditional medicine & 161 & 25.42 \\
\hline & $\begin{array}{l}\text { Use traditional medicine and drug from } \\
\text { pharmacy }\end{array}$ & 90 & 14.16 \\
\hline & $\begin{array}{l}\text { Use both traditional medicine and take to } \\
\text { veterinary clinic }\end{array}$ & 338 & 53.33 \\
\hline & Take to veterinary clinic only & 45 & 7.08 \\
\hline & All & 332 & 52.5 \\
\hline
\end{tabular}

\section{Attitude of Respondents Toward Pet Management}

From the total respondents, $76.15 \%$ of them strongly agreed with the benefits of pet owning over its risk. Moreover, $68.09 \%$ of respondents strongly agreed with the importance of pets to their family. It is likely that, in $49.13 \%$ of the current respondents, removal of a pet from the family by any reason could negatively affect them. In all attitude related responses there was a significant association $(p<0.05)$ between the number of respondents and the variable studied (Table 4$)$.

\section{Practice of Respondents Toward Pet Management}

In the current questionnaire surveys, $64.2 \%$ of the respondents had not accessed veterinary regular services for their pets. From the total respondents, $56.67 \%, 18.75 \%$, and $19.58 \%$ brought their pets to a veterinary clinic for vaccination, sickness, and both, respectively. However, $7.5 \%$ of the respondents did not take their pet to a veterinary clinic at all.

According to the findings, most respondents (44.2\%) feed their pets meat. Regarding the sources of meat, $28.3 \%$, $11.7 \%, 27.9 \%$, and $19.6 \%$ of the respondents provided the feed for their pets from backyard slaughtered meat, hunting, 
Table 4 Attitude of Respondents Toward Pet Management

\begin{tabular}{|c|c|c|c|c|}
\hline Variables & Response & Percentage (\%) & $\chi^{2}$ & $P$-value \\
\hline The benefits of pet ownership over its risk & $\begin{array}{l}\text { Strongly agree } \\
\text { Somewhat agree } \\
\text { Strongly disagree } \\
\text { Somewhat disagree } \\
\text { Doubtful }\end{array}$ & $\begin{array}{l}482(76.15) \\
140(22.12) \\
0(0.00) \\
2(0.31) \\
9(1.42)\end{array}$ & 19.57 & 0.02 \\
\hline Pets are an important part of the household & $\begin{array}{l}\text { Strongly agree } \\
\text { Somewhat agree } \\
\text { Strongly disagree } \\
\text { Somewhat disagree } \\
\text { Doubtful }\end{array}$ & $\begin{array}{l}431(68.09) \\
108(17.06) \\
36(5.69) \\
3(0.47) \\
55(8.69)\end{array}$ & 15.46 & 0.04 \\
\hline Deduction of pets would negatively affect the household & $\begin{array}{l}\text { Strongly agree } \\
\text { Somewhat agree } \\
\text { Strongly disagree } \\
\text { Somewhat disagree } \\
\text { Doubtful }\end{array}$ & $\begin{array}{l}311(49.13) \\
162(25.59) \\
21(3.32) \\
76(12.00) \\
63(9.95)\end{array}$ & 13.39 & 0.04 \\
\hline Concerned about diseases caught from pets & $\begin{array}{l}\text { Very concerned } \\
\text { Some concerned } \\
\text { Not concerned }\end{array}$ & $\begin{array}{l}466(73.62) \\
133(21.01) \\
34(5.37)\end{array}$ & 18.36 & 0.03 \\
\hline Concerned about diseases transferred from pets to children & $\begin{array}{l}\text { Very concerned } \\
\text { Some concerned } \\
\text { Not concerned }\end{array}$ & $\begin{array}{l}491(77.57) \\
112(17.69) \\
30(4.74)\end{array}$ & & \\
\hline
\end{tabular}

both back yard and hunting, and from leftovers, respectively. Additionally, $6.2 \%$ and 31.7\%, respectively, provided milk and both meat and milk. According to this survey analysis, 39.6\%, 10.4\%, 10.8\%, 4.2\%, and 35\% of the participants replied that pets slept in the living room, outside a compound, within a pet house, both in a pet house and with livestock, and totally with livestock, respectively. Regarding offal management, $47.4 \%, 27.9 \%$, and $23.7 \%$ of respondents replied that they used offal as feed for their pet, threw it away, or put it in a communal dumping area, respectively, as is shown in Table 5.

\section{Impact of Educational Level on Knowledge of the Respondents Toward Pet Management}

There was a significant interaction effect $(p<0.05)$ between the type of pet kept, the purpose for keeping, marital status, education, and occupation of the respondents' with respect to assessed variables. The percentage of non-formal education respondents letting their pets sleep in the living room was 39.6\% (251). No individuals without formal education provided independent houses for their pets. However, $10.38 \%$ of respondents with grade 5-8 level education provided their pets with independent houses. The level of education of the respondents is also significantly related to their practices of disposing of pet feces, where only $17.18 \%$ of non-formally educated and $14.67 \%$ of respondents in with gGrade $1-4$ education were disposing of the pet's waste in a communal waste disposal. Moreover, there was a significant difference among different educational levels of the respondent on the conditions to take pets to veterinary clinic (Table 6).

\section{Relationships Between KAP Scores and Demography of the Respondents}

In addition to assessing their knowledge, attitudes, and practices related to pet care, the respondents were also evaluated in relation to their demography. Accordingly, KAP scores were marginally $\left(\chi^{2}=8.828, p=0.048\right)$ correlated with job type. A statistically significant association between KAP scores and education level $\left(\chi^{2}=19.46, p=0.001\right)$ was observed. The good scores were higher $(60 \%)$ in the respondents having graduated college or university (Table 7$)$. 
Table 5 Practice of Respondents Toward Pet Management

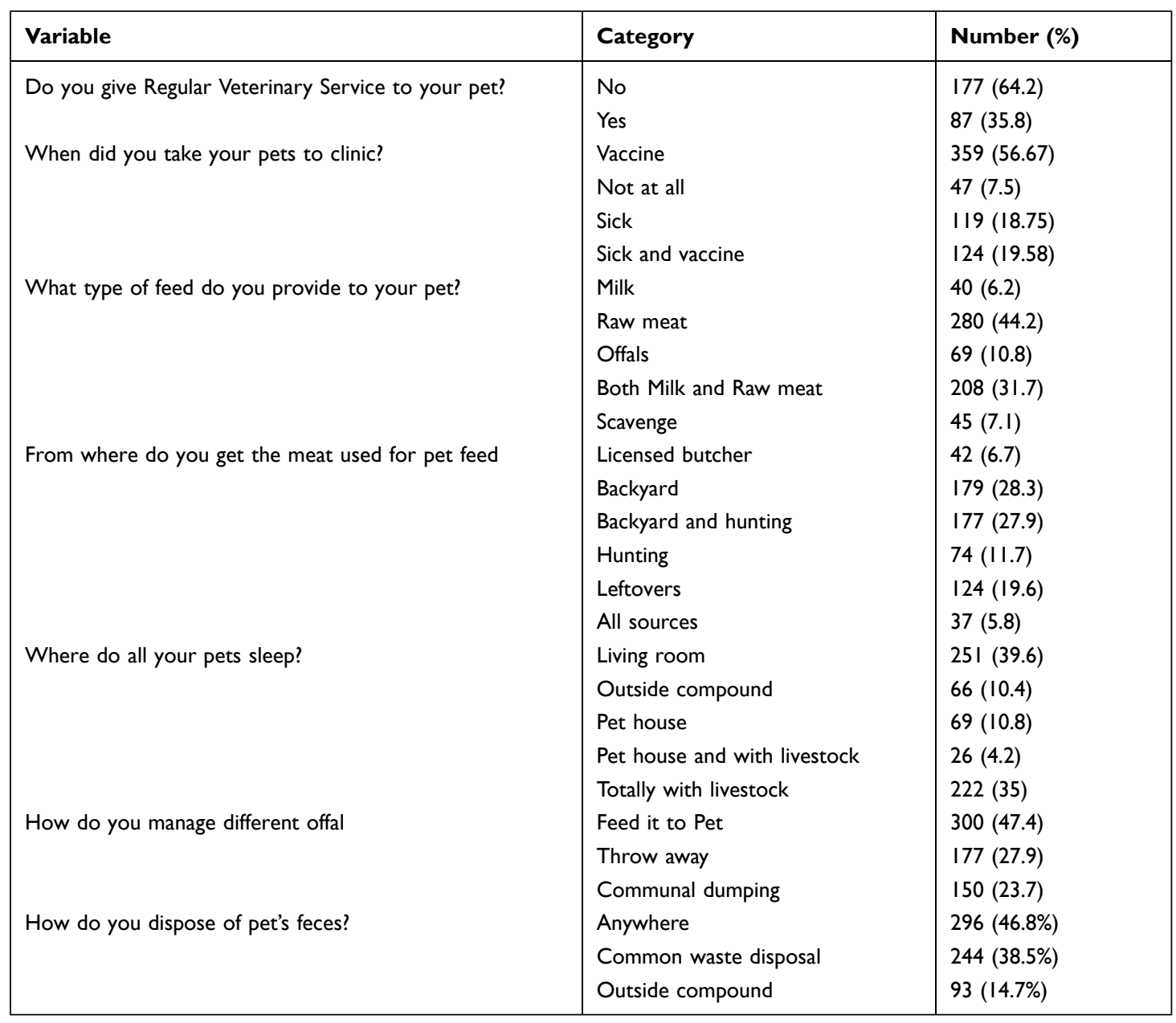

Table 6 Influence of Educational Level Against Practice of Respondents Toward Management Pet Associated Zoonosis

\begin{tabular}{|c|c|c|c|c|c|c|c|}
\hline \multirow[t]{2}{*}{ Variables } & \multicolumn{5}{|c|}{ Educational Status } & \multirow[t]{2}{*}{$\chi^{2}$} & \multirow[t]{2}{*}{$P$-value } \\
\hline & No Formal Education & G. I-4 & G.5-8 & G.10 & College/University & & \\
\hline Sleeping area: living room & 13 & 18 & 31 & 59 & 30 & 15.54 & 0.0486 \\
\hline Outside compound & 13 & 12 & 20 & 23 & 8 & & \\
\hline Pet house only & 3 & 13 & 23 & 21 & 5 & & \\
\hline Pet house and with livestock & 59 & 10 & 13 & 33 & 8 & & \\
\hline With livestock & 43 & 28 & 66 & 56 & 25 & & \\
\hline Feces disposal: Anywhere & 44 & 105 & 58 & 50 & 24 & 6.04 & 0.0196 \\
\hline Common waste disposal & 32 & 32 & 119 & 111 & 58 & & \\
\hline Offal management: Pet feed & 48 & 48 & 148 & 154 & 54 & 1.86 & $0.76 \mathrm{I}$ \\
\hline Throw away & 27 & 27 & 59 & 46 & 22 & & \\
\hline Regular vet services: Yes & 25 & 58 & 145 & 121 & 47 & 3.64 & 0.0457 \\
\hline No & 39 & 19 & 66 & 83 & 30 & & \\
\hline Conditions to clinic: Vaccine & 32 & 35 & 113 & 107 & 51 & 49.85 & 0.001 \\
\hline Sick & 19 & 19 & 51 & 27 & 5 & & \\
\hline Both & 5 & 11 & 40 & 56 & 13 & & \\
\hline Not at all & 19 & 11 & 5 & 8 & 6 & & \\
\hline
\end{tabular}

Abbreviations: G, grade; $\chi^{2}$, chi-square. 
Table 7 Relationship Between KAP Scores and per Study Participants

\begin{tabular}{|c|c|c|c|c|c|c|}
\hline \multicolumn{2}{|l|}{ Variable } & \multicolumn{2}{|l|}{ KAP Score } & \multirow{2}{*}{$\begin{array}{l}\text { Percentage } \\
142(22.4)\end{array}$} & \multirow{2}{*}{$\frac{\chi^{2}}{19.46}$} & \multirow{2}{*}{$\frac{p \text {-value }}{0.001}$} \\
\hline Educational status & No formal education & Good (\%) & Poor (\%) & & & \\
\hline & Grade I-4 & $82(58.49)$ & 61 (42.59) & $211(33.3)$ & & \\
\hline & Grade $5-8$ & $108(51.25)$ & $103(48.75)$ & $211(33.3)$ & & \\
\hline & Grade $10-12$ & $106(50)$ & $106(50)$ & $13(2.1)$ & & \\
\hline & College/university & $8(60)$ & $5(40)$ & $55(8.7)$ & & \\
\hline \multirow[t]{2}{*}{ Sex } & Male & $164(56.88)$ & $124(43.11)$ & $287(45.3)$ & 3.38 & 0.071 \\
\hline & Female & $190(54.96)$ & $156(45.03)$ & $346(54.7)$ & & \\
\hline \multirow[t]{2}{*}{ Age in years } & $<25$ & $153(47.54)$ & $169(52.45)$ & $322(50.9)$ & 0.44 & 0.30 \\
\hline & $\geq 25$ & $16 \mid(51.69)$ & $150(48.30)$ & $311(49.1)$ & & \\
\hline \multirow[t]{2}{*}{ Marital status } & Married & $243(47.92)$ & $264(52.08)$ & $506(79.9)$ & 1.067 & 0.33 \\
\hline & Unmarried & $71(56.25)$ & $55(43.75)$ & $127(20.1)$ & & \\
\hline \multirow[t]{3}{*}{ Job type } & Farmers & $185(51.09)$ & $177(48.90)$ & $362(57.2)$ & 8.828 & 0.048 \\
\hline & Merchant & $119(18.8)$ & $98(15.5)$ & $217(34.3)$ & & \\
\hline & Health professionals & $45(80.97)$ & II (23.53) & $55(8.7)$ & & \\
\hline
\end{tabular}

Abbreviations: KAP, knowledge, attitude and practice; $\chi^{2}$, chi-square.

\section{Discussion}

This study aimed to assess household knowledge, attitudes, and practices related to pet contact associated zoonosis among selected districts of East Wollega. Most of the respondents were female and aged over 25 years, indicating the importance of the female in the household controlling the whole family information. This finding is consistent with previous studies conducted by Wale ${ }^{21}$ around Bishoftu and Weldegerima et $\mathrm{al}^{22}$ in Mekelle city, in which female participants were found to total $56.6 \%$ and $56.4 \%$, respectively.

Moreover, in the current study, most of the households kept dogs; indicating this pet was found to be one of the most easily adapted pets from all animals in Ethiopia. This might have resulted in the occurrence of direct contact between these common household pets and human beings.

In the current survey the majority of the participants were aware of rabies being one of the pet contact associated diseases. This finding is consistent with previous reports of Weldegerima et $\mathrm{al}^{22}$ in Mekelle, Reta ${ }^{23}$ from Gonder City, and Bingham et $\mathrm{al}^{13}$ from Texas, where veterinarians and public health officials considered rabies to be a serious problem. This clearly supports that rabies is a well-established zoonotic disease in Ethiopia. ${ }^{24}$ Most of the respondents believe rabies to be solely transmitted by dogs and exercise different traditional management if a dog bites a human or animal member. As reported previously by Bingham et $\mathrm{al}^{13}$ from Texas and Fontaine et $\mathrm{al}^{24}$ from Georgia, the public appear informed about rabies, but less informed about other diseases like toxoplasmosis, hydatidosis, and ring worm.

According to the current study, biting, scratching, and wound contact with saliva are the common routes of transmission for rabies, as noted by Yimer et al, ${ }^{25}$ from Addis Ababa. Hands could be a source of yoxoplasma infection if they are not washed thoroughly, especially after contact with soil or cat feces, as this poses a risk of intentional ingestion of oocysts. ${ }^{26}$ Livestock, particularly sheep, serve as intermediate hosts for transmission of hydatidosis, while dogs act as a definitive host and transmit the diseases to humans through the fecal-oral route when oocysts are accidentally ingested. ${ }^{27,28}$ Ring worm can be transmitted from pets to humans during playing with pets and petting if a person is unable to properly their wash hands, especially to young children. ${ }^{29}$ Children especially have close contact with the fecal matter of pets because of walking bare foot or their normal play being around areas with pet feces. In this regard, addressing safe pet interaction training and rabies prevention strategies need to be addressed.

The majority of the respondents acquired information about pet associated zoonosis from their neighbor or informal social network. There are few respondents who got formal training from health professionals. Conversely, studies conducted by Bingham et $\mathrm{al}^{13}$ in the United States and Palmer et $\mathrm{al}^{30}$ in Australia indicate that media outlets and professionals are the two most common sources of information. This finding is in line with the previous reports of Abraham et al, ${ }^{31}$ Deressa et al, ${ }^{32}$ 
Wudu et al, ${ }^{33}$ Tadesse et al, ${ }^{34}$ and Admasu and Mekonnin, ${ }^{35}$ conducted in different corners of Ethiopia in which for the majority of respondents information was from informal sources, traditional healers, and friends. Recently, a pet contact associated zoonosis control program has been very rare in Ethiopia, which could probably explain the limited knowledge about those diseases and their prevention and control. The limited zoonotic disease knowledge of the public is a serious issue because awareness of the risk of zoonotic diseases is a prerequisite for effective prevention.

One fourth of the respondents indicated use of traditional medicine in order to treat and control pet contact associated zoonosis. This finding was in agreement with a report by Kiflu et $\mathrm{al}^{36}$ in Addis Ababa. In Ethiopia a wide range of conventional treatments for bites by dogs suspected of being rabied were utilized, focusing mostly on human patients, but dogs and other domestic animals were also treated before being rabied. The purgative impact of giving the traditional drug through the oro-gastrointestinal tract was considered to be the basis for traditional medicine remedies. The nonstandardization of ingredients, purity, and efficacy of these traditionally used antirabies herbal treatments are the major difficulties documented by Ethiopian health institute research. ${ }^{36}$

Most of the respondents strongly agreed with the benefits of pet ownership, with the death of them negatively affecting the household in one or different ways. On the other hand, they wee very concerned about diseases transmitted from pets. Though the benefits outweigh the risk, pets can bring different Zoonotic infections to households, particularly cats carry the toxoplasma parasite which can get into the brain and cause toxoplasmosis. People with a compromised immune system are especially vulnerable to this. Pets can also cause allergic reactions in some pet owners. ${ }^{37,38}$ Dogs can be a host for different numbers of pathogenic flea, louse, mite, tick, fly ectoparasite, tape worm, and gastrointestinal endoparasites. ${ }^{39}$ Therefore, effective control and hygienic programs need to be practiced to ensure the good welfare of humans and animals.

Raw feed is becoming increasingly popular with companion animals, which can pose a serious zoonotic risk. These diets and their ingredients have been found to be contaminated with pathogenic microorganisms, as indicated in a study conducted by Larry et al. ${ }^{40}$ From the current result, it is revealed that the majority of the respondents provided raw meat for their pets as food. There is a greater amount of feeding raw meat to pets in the current report than in a previous report in Canada which revealed only $28 \%$ of pet owners' feed raw meat to dogs. ${ }^{6}$ Feeding a raw meat to dogs is important in the completion of the lifecycle of hydatidosis.

In Ethiopia, pet management patterns are extremely difficult to define, which is mainly due to them not being controlled with strict sanitation. This indicates that the likelihood of transmission for pet contact associated zoonosis to humans is very high. Moreover, the practice of allowing dogs to roam freely both outside and in living room would facilitate the spread of pet associated diseases, according to Larry et al. ${ }^{40}$ In line with this, most of the respondents mentioned that they used offal as a source of pet food, as also reported by Reta ${ }^{23}$ around Gondor. Because of a large number of stray dogs and inappropriate offal management in the community it is very likely that garbage offal is eaten by dogs, increasing the rate of zoonotic disease from pets.

Management aspects of pets, as well as respondents' education levels, were assessed to measure how well they knew, perceived, and practiced pet management. The educational findings is generally were found to be consistent with previous studies by Kiflu et $\mathrm{al}^{36}$ and Memon et al. ${ }^{19}$ There was a significant association between KAP scores with respect to education level and job types.

\section{Conclusion}

The current study characterized and assessed household knowledge, attitude, and risks related to pet contact associated zoonosis. In conclusion, the respondents indicated that rabies was a common pet contact associated zoonosis, along with toxoplasmosis, hydatidosis, and ring worm. Moreover the study also indicated the importance of pet ownership though transmitting different zoonotic disease. The tradition of providing raw meat to pets was found to be common, which may result in creating a favorable environment for completing the lifecycle of zoonotic parasites. The flow of information via informal ways resulted in different knowledge, attitudes, and practice levels of households. Finally, different intervention to improve the awareness of households on knowledge, attitude, and practices toward pet contact associated zoonotic disease needs to be implemented. 


\section{Data Sharing Statement}

The data used to support these finding are included within the article.

\section{Ethics Approval and Consent to Participate}

Before starting the interview, oral consent was obtained from the pet owners after verbal informed consent was approved by the Wollega University ethics committee. The participants were informed about the purpose of the study and parental/ legal guardian informed consent was obtained for participants under the age of 18 .

\section{Acknowledgments}

Our deepest gratitude goes to Wollega University research and technology transfer office for supporting the research work through financial support.

\section{Author Contributions}

All authors made a significant contribution to the work reported, whether that is in the conception, study design, execution, acquisition of data, analysis and interpretation, or in all these areas; took part in drafting, revising, or critically reviewing the article; gave final approval of the version to be published; have agreed on the journal to which the article has been submitted; and agree to be accountable for all aspects of the work.

\section{Funding}

This study was funded by Wollega University research office. Outside of the listed authors, Wollega University played no role in the design of the study, or in writing of this manuscript.

\section{Disclosure}

The authors declare that they have no competing interests in this work.

\section{References}

1. Song SJ, Lauber C, Costello EK, et al. Cohabiting family members share microbiota with one another and with their dogs. eLife. 2013;2:e00458. doi:10.7554/eLife.00458

2. McPherron SP, Alemseged Z, Marean CW, et al. Evidence for stone-tool-assisted consumption of animal tissues before 3.39 million years ago at Dikika, Ethiopia. Nature. 2010;466:857-860. doi:10.1038/nature09248

3. World Health Organization. The control of neglected zoonotic diseases. Report of a joint WHO/DFIDAHP meeting with the participation of FAO and OIE. Geneva; 2006. Available from: http://whqlibdoc.who.int/publications/2006/9789241594301_eng.pdf. Accessed January 13, 2021.

4. Walsh F. Human-animal bonds I: the relational significance of companion animals. Fam Process. 2009;48(4):462-480. doi:10.1111/j.15455300.2009.01296.x

5. Nkuchia MM, Ruth L, Chris AB, Henriette V. Infectious Disease Surveillance. Malden, Massachusetts 02148-5020 USA: Blackwell Publishing Inc; 2007:246-248.

6. Stull J, Peregrine AS, Sargeant M, Weese JS. Husbandry and Infection Control Practices Related to Zoonotic Disease Risks in Ontario. Canada. BMC Public Health. 2013;13(1):1-5.

7. Patronek GJ, Slavinski SA. Animal bites. J Am Vet Med Assoc. 2009;234(3):336-345. doi:10.2460/javma.234.3.336

8. Oehler RL, Velez AP, Mizrachi M, Lamarche J, Gompf S. Bite-related and septic syndromes caused by cats and dogs. Lancet Infect Dis. 2009;9 (7):439-447. doi:10.1016/S1473-3099(09)70110-0

9. CDC. Epidemiology \& risk factors, page last reviewed: September 4, 2018, content source: global health, division of parasitic diseases and Malaria; 2018

10. World Health Organization. Managing zoonotic public health risks at the human animal-ecosystem interface. Strong inter-sectoral partnerships in health. Food safety and zoonoses; 2010. Available from: www.who.int/foodsafety. Accessed January 13, 2022.

11. Gebreselasie D, Geyola M, Dagne E, Asmare K, Mekuria S. Gastrointestinal helminthes in dogs and community perception on parasite zoonosis at hawassa city, Ethiopia. Global Veterinaria. 2013;11(4):432-440.

12. Mboussou F, Ndumbi P, Ngom R, et al. Infectious disease outbreaks in the African region: overview of events reported to the World Health Organization in. Epidemiol Infect. 2019;147:e299.

13. Bingham G, Budke C, Slater M. Knowledge and Perceptions of Dog-Associated Zoonoses. Brazos County, Texas, USA. Prev Vet Med. 2010;93(23):211-221.

14. World Health Organization. The Control of Neglected Zoonotic diseases; 2011. Available from: http://apps.who.int/iris/bitstream/handle/10665/ 44746/9789241502528_eng.pdf;jsessionid=06F0847746BD3BDE5466628CBEFC9FFE?sequence=1. Accessed January 24, 2022.

15. Brooker S, Clements A, Bundy D. Global epidemiology and ecology control of soil transmitted helminth infections. Adv Parasitol. 2006;62:221-261. 
16. Zoonotic disease prioritization for inter-sectoral engagement in Ethiopia September 29-30; 2015.

17. Chomel BB, Sun B. Zoonoses in the bed room. Emerg Infect Dis. 2011;17(2):167-172. doi:10.3201/eid1702.101070

18. EWZFDOS (East Wollega Zone Finance Development Office and Socio-economics. Zonal Abstract Report. Nekemte; 2020.

19. Memon MS, Shaikh SA, Shaikh AR, Fahim MF, Mumtaz N, Ahmed N. An assessment of knowledge, attitude and practices (KAP) towards diabetes and diabetic retinopathy in a suburban town of Karachi. Pak J Med Sci. 2015;31(1):183-188. doi:10.12669/pjms.311.6317

20. Ali A, Ahmed EY, Sifer D. A study on knowledge, attitude and practice of rabies among residents in Addis Ababa, Ethiopia. Ethiop Vet J. 2013;17 (2):19-35. doi:10.4314/evj.v17i2.2

21. Wale FT. Household knowledge, attitudes and practices related to pet contact and associated zoonosis in Bishoftu, Ethiopia. Global Veterinaria. 2017;18(4):277-285.

22. Weldegerima G, Kindie F, Gebru GG, Kebede A. Assessment of Knowledge, Attitude and Practice Towards Rabies and Associated Factors Among Household Heads in Mekelle City. EthiopiaBMC public health. 2020;20(1):1-7.

23. Reta T. Knowledge, attitudes and practices towards rabies: questionnaire survey in rural household heads of Gondar Zuria District, Ethiopia. BMC Res. 2015;8:400.

24. Fontaine RE, Schantz PM. Pet ownership and knowledge of zoonotic diseases in De Kalk County, Georgia. Anthrozoos. 1988;3:45-49. doi:10.2752/089279390787057720

25. Yimer E, Mesfin A, Beyene M, et al. Study on knowledge, attitude and dog ownership patterns related to rabies prevention and control in Addis Ababa, Ethiopia. Ethiop Vet J. 2012;17(2):27-39.

26. Ngui R, Lim YAL, Amir NFH, Nissapatorn V, Mahmud R. Seroprevalence and sources of toxoplasmosis among Orang Asli (indigenous) communities in Peninsular Malaysia. Am J Trop Med Hyg. 2011;85:660-666. doi:10.4269/ajtmh.2011.11-0058

27. Li D, Gao Q, Liu J, et al. Knowledge, attitude, and practices (KAP) and risk factors analysis related to cystic echinococcosis among residents in Tibetan communities, Xiahe County, Gansu Province, China. Acta Trop. 2015;147:17-22. doi:10.1016/j.actatropica.2015.02.018

28. Coyle CM, Junghanss T. Cystic Echinococcosis. In: Hunter's Tropical Medicine and Emerging Infectious Diseases. Elsevier; $2020: 946-953$.

29. Kaplan W. Epidemiology and public health significance of ringworm in animals external icon. Arch Dermatol. 1967;96(4):404-408. doi:10.1001/ archderm.1967.01610040054010

30. Palmer CS, Robertson ID, Traub RJ, Rees R, Thompson RC. Intestinal parasites of dogs and cats in Australia: the veterinarian's perspective and pet owner awareness. Vet J. 2010;183:358-361. doi:10.1016/j.tvj1.2008.12.007

31. Abraham A, Eshetu YA, Desalegn S. A study on knowledge, attitude and practice of rabies among residents in Addis Ababa, Ethiopia. Ethiop Vet J. 2013;17(2):19-35.

32. Deressa A, Ali A, Beyene M, Newaye SB, Yimer E. The status of Rabies in Ethiopia: a retrospective record review. Ethiop J Health Dev. 2010;24:127-132. doi:10.4314/ejhd.v24i2.62961

33. Wudu T, Kelay B, Mekonnen HM, Tesfu K. Calf morbidity and mortality in smallholder dairy farms in Ada'aliben district of Oromia, Ethiopia. Trop Anim Health Prod. 2008;40:369-376. doi:10.1007/s11250-007-9104-3

34. Tadesse G, Anmaw S, Mersha C, Basazinew B, Tewodros F. Assessment of knowledge, attitude and practices about rabies and associated factors: in the case of Bahir Dar Town. Global Veterinaria. 2014;13(3):348-354.

35. Admasu P, Mekonne Y. Rabies and its folk drugs remedies in Ethiopia: A review, international. J Basic Applied Virol. 2014;3(2):22-27. 2014ISSN 2222-1298 (C) IDOSI Publications.

36. Kiflu B, Abdurahaman M, Alemayehu H, Eguale T. Investigation on public knowledge, attitude and practices related to pet management and zoonotic canine diseases in Addis Ababa, Ethiopia. Ethiop Vet j. 2016;20(1):67-78. doi:10.4314/evj.v20i1.5

37. Katagiri S, Oliveira-Sequeira T. Prevalence of dog intestinal parasites and risk perception of zoonotic infection by dog owners in São Paulo State, Brazil. Zoonoses Public Health. 2008;55(8-10):406-413. doi:10.1111/j.1863-2378.2008.01163.x

38. Moriello KA. Zoonotic skin diseases of dogs and cats. Anim Health Res Rev. 2003;4(2):157-168. doi:10.1079/AHRR200355

39. Dantas-Torres F, Otranto D. Dogs, cats, parasites, and humans in Brazil: opening the black box. Parasit Vectors. 2014;7(1):22. doi:10.1186/17563305-7-22

40. Larry LK, Joseph N, Frederick JA; Committee on Infectious Diseases. Exposure to nontraditional pets at home and to animals in public settings: risks to children. Pediatrics. 2008;122(4):876-886. doi:10.1542/peds.2008-1942

Veterinary Medicine: Research and Reports

Dovepress

\section{Publish your work in this journal}

Veterinary Medicine: Research and Reports is an international, peer-reviewed, open access journal publishing original research, case reports, editorials, reviews and commentaries on all areas of veterinary medicine. The manuscript management system is completely online and includes a very quick and fair peer-review system. Visit http://www.dovepress.com/testimonials.php to read real quotes from published authors.

Submit your manuscript here: http://www.dovepress.com/veterinary-medicine-research-and-reports-journal 